\title{
Influence of abiotic factors on some biological and ecological characteristics of the aphid parasitoid Aphelinus asychis (Hymenoptera: Aphelinidae) parasitizing Aphis gossypii (Sternorrhyncha: Aphididae)
}

\author{
Stefanie SCHIRMER*, Cetin SENGONCA* and Peter BLAESER
}

Department of Entomology and Plant Protection, Section Phytomedicine, Institute of Crop Science and Resource Conservation, University of Bonn, Nussallee 9, D-53115 Bonn, Germany; e-mails: C.Sengonca@uni-bonn.de, s.schirmer@uni-bonn.de

Key words. Aphelinidae, Aphelinus asychis, Japanese strain, Aphis gossypii, cotton aphid, biological control, biology, development, fecundity, host feeding, light intensity, temperature, relative humidity

\begin{abstract}
The current laboratory study was designed to evaluate the effect of abiotic and biotic factors such as temperature, light intensity, relative humidity and host age on biological and ecological characteristics of Aphelinus asychis (Walker) parasitizing Aphis gossypii (Glover). The traits studied were developmental duration, mortality, sex ratio, longevity, fecundity and host feeding. A. asychis can completely develop and reproduce at temperatures $18^{\circ} \mathrm{C}$ and $30^{\circ} \mathrm{C}$, light intensities of 1000 and 7000 lux and relative humidities of $30 \%$ and $60 \%$. Temperature had a significant effect on the developmental duration as well as on the percentage and longevity of females, while mortality from mummification to emergence, fecundity and host feeding were only slightly affected. Relative humidity only affected the developmental duration of $A$. asychis. Light intensity had mostly affected the biological and ecological traits of $A$. asychis. High light intensity resulted in a shorter developmental duration, higher incidence of females and longer life span of the female parasitoid. A high tolerance to climatic variations and life cycle well adapted to this aphid host are properties that make it likely that $A$. asychis could be used for the biological control of the cotton aphid in greenhouses.
\end{abstract}

\section{INTRODUCTION}

The cotton aphid, Aphis gossypii Glover (Sternorrhyncha: Aphididae), is a phytophagous cosmopolitan species widely distributed in tropical, subtropical and temperate regions. It is a major pest of many cultivated plants such as Cucurbitaceae, Rutaceae and Malvaceae. In Europe, the cotton aphid is an important agricultural pest of cucumber and some other greenhouse crops (Van Schelt 1993). Because of the increasing insecticide resistance of pests (Furk \& Hines, 1993; Villatte et al., 1999; Wang et al., 2001) current research is directed towards the use of biological control. Despite numerous studies of aphidophagous insects, only a few of them are suitable for use as biological control agents in greenhouses on a large scale because they do not always match the reproductive and developmental rates of aphids (Van Steenis, 1995b). A knowledge of the influence of abiotic factors on the biological and ecological traits of a potential natural enemy is important for determining whether the natural enemy is likely to be effective in the new environment. Temperature is an important abiotic factor and in the case of parasitoids, light intensity also affects parasitization success. For example, Encarsia formosa Gahan (Hymenoptera: Aphelinidae), a parasitoid of the white fly Trialeurodes vaporariorum (Westwood) (Homoptera: Aleyrodidae) is very sensitive to light. Laboratory studies by McDevitt (1973) indicate that this parasitoid laid few eggs at light intensities below 4200 lux, and only at 7300 lux is this parasitoid fully reproductive. Moreover Van Lenteren et al. (1992) record that E. formosa was able to disperse at high (8000 lux) and low (500 lux) light intensities but covers greater distances at high light intensities. Several authors describe the effect of day length on Aphelinus species (Yu, 1992; Bernal et al., 2001; Tatsumi \& Takada, 2005b, 2006), but the influence of light intensity is unknown.

One promising candidate for the biological control of the cotton aphid is a Japanese strain of the aphelinid parasitoid, Aphelinus asychis Walker (Hymenoptera: Aphelinidae) (Sengonca et al., 2007). A. asychis is a solitary endoparasitoid of aphids and it is able to reproduce parthenogenetically. In addition to ovipositing in aphids, $A$. asychis females immobilize some aphids by stinging them and then feed on their hemolymph and other tissues. This trait is called host feeding and it is necessary for the production of eggs and it prolongs survival of females (Bai \& Mackauer, 1990a). This species is widely distributed in Europe, Asia and North America and is known to parasitize many species of aphids such as cereal aphids, Myzus persicae Sulzer and Acyrthosiphon pisum Harris (Sternorrhyncha: Aphididae) (Jackson \& Eikenbary, 1971; Raney et al., 1973; Zohdy, 1976; Bai \& Mackauer, 1990a,b). More recent studies reveal that $A$. asychis is also able to parasitize the cotton aphid, A. gossypii (Elliott et al., 1999; Tatsumi \& Takada, 2005a). Sengonca et al. (2007) recently examined some life table characteristics of this parasitoid and described the influence different host ages have on its biological and ecological traits. In order to maximize its successful use in biological control it is

\footnotetext{
* Authors for correspondence.
} 
important to conduct detailed studies on the influence of different abiotic factors on the biology and ecology of this potential biocontrol agent. However, there is a lack of detailed knowledge of the effects of some climatic factors on the biology and ecology of $A$. asychis parasitizing $A$. gossypii.

Therefore, the aim of the present study was to evaluate the influence of temperature, relative humidity and light intensity as well as host age on the development, mortality, sex ratio, longevity, fecundity and host feeding of $A$. asychis parasitizing the cotton aphid.

\section{MATERIAL AND METHODS}

\section{Insect rearing}

The stock culture of $A$. gossypii was established with individuals obtained from the Institute of Crop Science and Resource Conservation, University of Bonn and was reared on cotton plants in climate chambers at $25 \pm 1{ }^{\circ} \mathrm{C}, 60 \pm 10 \% \mathrm{RH}$ and a photoperiod of $16 \mathrm{~L}: 8 \mathrm{D}$. Two different age groups of the aphid, 1-2 and 4-5 day old nymphs were used in the experiments. While 1-2 day old aphids consisted of first and second instar individuals, 4-5 day old aphids consisted predominantly of fourth instar individuals. Neither adults nor alate individuals were used in the experiments. The aphid nymphs were obtained by using freshly excised cucumber leaf discs, about $4.5 \mathrm{~cm}$ in diameter, which were placed upside down on top of a $0.7 \%$ layer of agar gel in round Plexiglas Petri dishes. The Petri dishes were about $5 \mathrm{~cm}$ in diameter $\times 1.8 \mathrm{~cm}$ in height and had a meshcovered hole in the lid to allow air exchange. A moistened fine camel hair brush was used to place gently up to ten young adult virginoparous $A$. gossypii individuals in each Petri dish. These females were left in the Petri dishes for $24 \mathrm{~h}$. Their offspring were then reared to the desired age at $25 \pm 1^{\circ} \mathrm{C}$.

The stock culture of $A$. asychis was started with few individuals obtained from Kyoto Prefectural University in Kyoto, Japan. They were originally collected from A. gossypii on Cucumis sativus in Kyoto, Kyoto Prefecture (Tatsumi \& Takada, 2005a ). The parasitoids were reared in climate chambers under the same climatic conditions as described above on A. pisum, feeding on broad beans, Vicia faba L. New aphids were added twice weekly. In order to obtain suitable hosts, a separate culture of pea aphids was maintained under identical conditions. For the experiments, a few adult females were taken from the stock culture and transferred to an A. gossypii culture feeding on cucumber in order to adapt the parasitoid to this aphid host. After three generations, mummified aphids were put individually into small glass vials $(1 \mathrm{~cm}$ in diameter $\times 7 \mathrm{~cm}$ in length), sealed with Parafilm ${ }^{\circledR} \mathrm{M}$, and checked for adult emergence every day. The parasitoids $(0-24 \mathrm{~h}$ old) were sorted by sex, and before starting the experiments females were presented to males for mating for $6 \mathrm{~h}$ in the same glass vials described above.

\section{Experimental procedures}

All experiments were conducted at two constant temperatures of $18 \pm 1{ }^{\circ} \mathrm{C}$ and $30 \pm 1{ }^{\circ} \mathrm{C}(\mathrm{RH}: 60 \pm 10 \% ; 3000 \pm 100$ lux $)$, at two light intensities of $1000 \pm 100$ lux and $7000 \pm 100$ lux (RH: $60 \pm 10 \% ; 25 \pm 1{ }^{\circ} \mathrm{C}$ ) as well as at $30 \pm 10 \%$ and $60 \pm 10 \%$ relative humidity $\left(25 \pm 1{ }^{\circ} \mathrm{C} ; 3000 \pm 100 \mathrm{lux}\right)$. Illumination was provided by high pressure sodium lamps HPS (Philips SON-T-AGRO 400). The spectrum of the light from those lamps is similar to that of visible light but with a high intensity of yellow and red light (approx. 550-660 nm). The relative humidity was achieved by putting bowls of water in the climate chambers. In addition, a hygrometer was used for monitoring.

In order to determine the duration of development, mortality and sex ratio of $A$. asychis, ten mated females (6-30 h old) were placed singly for $24 \mathrm{~h}$ in round Plexiglas Petri dishes (see above) containing 50 individuals of either 1-2 or 4-5 day old $A$. gossypii nymphs on cucumber leaf discs and kept in the climatic conditions described above. After removal of the parasitoid the aphids were kept in an incubator under the same constant climatic conditions and checked once per day at the same hour for mummification. Mummified aphids were transferred to small glass vials, like those used for rearing, until adult emergence. Developmental duration from egg to mummification, mummification to adult emergence and mortality during development from mummification to adult emergence was determined. The larva develops as a solitary endoparasite and pupation takes place inside the dead host, which is transformed into a bluishblack mummy (Bai \& Mackauer, 1990a; Brodeur \& Rosenheim, 2000). Thus, the developmental period from egg to mummification represents the period required for larval development and the period from mummification to adult emergence referred to as pupal development. Mummification in this experiment was defined as hardening and blackening of the body. The sex ratio of $A$. asychis was calculated by determining the percentage of females in the total progeny of all ten females in the same experiment. Only those females that produced one or more female offspring were considered as mated. Based upon previous studies, unmated female parasitoids produced only male progeny (Raney et al., 1971). Results for unmated females were excluded from statistical analysis.

For recording longevity, fecundity and host feeding by the female parasitoid, ten mated $A$. asychis females $(6-30 \mathrm{~h}$ old) were offered daily a number of 20-50 A. gossypii nymphs (1-2 day old) throughout their life span. The number of aphids provided depended on the age of the parasitoid, as revealed in previous studies. A. asychis females were transferred daily into new round Plexiglas Petri dishes with fresh aphids and the number of aphids killed by host feeding recorded. The old Petri dishes were returned to the incubator and after 3-4 days all aphids were dissected and the number of parasitoid larvae counted.

\section{Statistical analysis}

The influence of host age was analysed using SPSS-12.0G (SPSS inc. 1989-2003). Differences among the means of developmental duration, mortality, longevity, reproduction and host feeding were tested using a t-test at a probability level of $\mathrm{p} \leq$ 0.05 . Data sets that did not fulfill the assumption of a normal distribution were statistically analysed using the nonparametrical Mann-Whitney-U-Test. For evaluating significant differences in the sex ratio a chi-square-test was used.

\section{RESULTS}

The results indicate that $A$. asychis can develop in $A$. gossypii and reach the adult stage at all the temperatures, light intensities and relative humidities used. The developmental duration from egg to mummification and mummification to adult, as well as the total developmental duration under different climatic conditions are summarized in Table 1 . When parasitizing the same age of the host, the mean developmental duration at $18^{\circ} \mathrm{C}$ was significantly longer than at $30^{\circ} \mathrm{C}$ for all immature stages. The same significant differences were recorded in the total developmental duration from egg to adult emergence. They varied from 11.3-24.6 days. Further- 
TABLE 1. Mean duration of development of immature stages of Aphelinus asychis parasitizing Aphis gossypii nymphs of different ages at different temperatures, relative humidities and light intensities.

\begin{tabular}{|c|c|c|c|c|c|c|c|c|}
\hline \multirow{3}{*}{$\begin{array}{l}\text { Abiotic } \\
\text { factors }\end{array}$} & \multirow{3}{*}{$\begin{array}{c}\text { Host } \\
\text { age } \\
\text { (days) }\end{array}$} & \multirow{3}{*}{$\mathrm{n}$} & \multicolumn{6}{|c|}{ Developmental duration (days) } \\
\hline & & & \multicolumn{2}{|c|}{ Egg - Mummy } & \multicolumn{2}{|c|}{ Mummy - Adult } & \multicolumn{2}{|c|}{ Total } \\
\hline & & & mean $\pm \mathrm{SE}$ & $\min -\max$ & mean $\pm \mathrm{SE}$ & $\min -\max$ & mean $\pm \mathrm{SE}$ & $\min -\max$ \\
\hline \multicolumn{9}{|c|}{ Temperature $\left({ }^{\circ} \mathrm{C}\right)$} \\
\hline \multirow[t]{2}{*}{$18 \pm 1$} & $1-2$ & 185 & $13.0 \pm 0.2 \mathrm{aA}$ & $9-18$ & $11.3 \pm 0.1 \mathrm{aA}$ & $8-14$ & $24.6 \pm 0.2 \mathrm{aA}$ & $20-32$ \\
\hline & $4-5$ & 250 & $9.6 \pm 0.1 \mathrm{aB}$ & $5-14$ & $11.5 \pm 0.1 \mathrm{aA}$ & $9-15$ & $21.0 \pm 0.1 \mathrm{aB}$ & $16-28$ \\
\hline \multirow[t]{2}{*}{$30 \pm 1$} & $1-2$ & 156 & $5.9 \pm 0.1 \mathrm{bA}$ & $5-8$ & $5.4 \pm 0.1 \mathrm{bB}$ & $3-7$ & $11.9 \pm 0.1 \mathrm{bA}$ & $10-16$ \\
\hline & $4-5$ & 147 & $5.8 \pm 0.1 \mathrm{bA}$ & $5-8$ & $5.4 \pm 0.1 \mathrm{bB}$ & $4-7$ & $11.3 \pm 0.1 \mathrm{bB}$ & $10-14$ \\
\hline \multicolumn{9}{|c|}{ Relative humidity (\%) } \\
\hline \multirow[t]{2}{*}{$30 \pm 10$} & $1-2$ & 287 & $6.0 \pm 0.0 \mathrm{aA}$ & $5-8$ & $6.3 \pm 0.0 \mathrm{aA}$ & $5-8$ & $12.4 \pm 0.0 \mathrm{aA}$ & $11-15$ \\
\hline & $4-5$ & 480 & $6.2 \pm 0.0 \mathrm{aB}$ & $5-8$ & $6.0 \pm 0.0 \mathrm{aB}$ & $4-8$ & $12.2 \pm 0.0 \mathrm{aB}$ & $10-15$ \\
\hline \multirow[t]{2}{*}{$60 \pm 10$} & $1-2$ & 303 & $7.3 \pm 0.0 \mathrm{bA}$ & $6-11$ & $6.9 \pm 0.0 \mathrm{bA}$ & $5-9$ & $14.4 \pm 0.1 \mathrm{bA}$ & $11-17$ \\
\hline & $4-5$ & 79 & $6.8 \pm 0.1 \mathrm{bB}$ & $5-8$ & $6.4 \pm 0.1 \mathrm{bB}$ & $4-9$ & $13.2 \pm 0.2 \mathrm{bB}$ & $11-17$ \\
\hline \multicolumn{9}{|c|}{ Light intensity (lux) } \\
\hline \multirow[t]{2}{*}{$1000 \pm 100$} & $1-2$ & 184 & $7.2 \pm 0.1 \mathrm{aA}$ & $6-10$ & $6.7 \pm 0.0 \mathrm{aA}$ & $5-9$ & $13.9 \pm 0.1 \mathrm{aA}$ & $12-17$ \\
\hline & $4-5$ & 199 & $9.6 \pm 0.1 \mathrm{aB}$ & $8-12$ & $7.8 \pm 0.1 \mathrm{aB}$ & $6-11$ & $17.4 \pm 0.1 \mathrm{aB}$ & $14-21$ \\
\hline \multirow[t]{2}{*}{$7000 \pm 100$} & $1-2$ & 315 & $6.6 \pm 0.0 \mathrm{bA}$ & $5-9$ & $6.7 \pm 0.0 \mathrm{bB}$ & $5-9$ & $13.3 \pm 0.1 \mathrm{bA}$ & $11-16$ \\
\hline & $4-5$ & 390 & $6.8 \pm 0.0 \mathrm{bB}$ & $5-10$ & $6.7 \pm 0.0 \mathrm{bB}$ & $5-9$ & $13.6 \pm 0.0 \mathrm{bB}$ & $12-17$ \\
\hline
\end{tabular}

Means with different lower case letters indicate significant differences between temperatures, relative humidities or light intensities and means with different capital letters indicate differences between host ages at $\mathrm{p} \leq 0.05 \%$ (t-test).

more, the results demonstrated that the relative humidity had a significant effect on the immature development of A. asychis.

The mean total developmental duration at $30 \% \mathrm{RH}$ was 12.4 and 12.2 days, and at $60 \%$ RH 14.4 and 13.2 days, when 1-2 or 4-5 day old aphid nymphs were used as hosts, respectively. Regarding light intensity, the mean developmental duration was significantly shorter at 7000 than at 1000 lux. The total developmental duration varied between 13.3 and 17.4 days. The results indicate that under the same climatic conditions, A. asychis completed its development in a significantly shorter period when it parasitized 4-5 rather than 1-2 day old A. gossypii nymphs.

The mortality during development (from mummification to adult emergence) and mean percentage of females at all climatic conditions for both host age groups is summarized in Table 2. Depending on temperature, the mortality tended to increase with increasing temperature, but not significantly. Relative humidity had no effect on mortality, while light intensity did as parasitoids developing in the younger hosts experienced greater mortality at

TABLE 2. Mean percentage mortality (from mummification to adult emergence) and percentage of females of Aphelinus asychis parasitizing Aphis gossypii nymphs of different ages at different temperatures, relative humidities and light intensities.

\begin{tabular}{|c|c|c|c|c|c|}
\hline \multirow{3}{*}{$\begin{array}{l}\text { Abiotic } \\
\text { factors }\end{array}$} & \multirow{3}{*}{$\begin{array}{c}\text { Host } \\
\text { age } \\
\text { (days) }\end{array}$} & \multicolumn{4}{|c|}{ Developmental duration (days) } \\
\hline & & \multicolumn{2}{|c|}{ Mortality (\%) } & \multicolumn{2}{|c|}{ Percentage of females (\%) } \\
\hline & & mean $\pm \mathrm{SE}$ & $\min -\max$ & mean $\pm \mathrm{SE}$ & $\min -\max$ \\
\hline \multicolumn{6}{|c|}{ Temperature $\left({ }^{\circ} \mathrm{C}\right)$} \\
\hline \multirow[t]{2}{*}{$18 \pm 1$} & $1-2$ & $19.2 \pm 4.4 \mathrm{aA}$ & $0-40$ & $17.9 \pm 2.6 \mathrm{bA}$ & $7-33$ \\
\hline & $4-5$ & $23.4 \pm 5.4 \mathrm{aA}$ & $5-67$ & $27.6 \pm 5.6 \mathrm{bA}$ & $6-67$ \\
\hline \multirow[t]{2}{*}{$30 \pm 1$} & $1-2$ & $31.5 \pm 9.8 \mathrm{aA}$ & $0-82$ & $38.0 \pm 4.3 \mathrm{aA}$ & $17-63$ \\
\hline & $4-5$ & $39.4 \pm 5.7 \mathrm{aA}$ & $8-62$ & $49.2 \pm 3.8 \mathrm{aA}$ & $31-64$ \\
\hline \multicolumn{6}{|c|}{ Relative humidity (\%) } \\
\hline \multirow[t]{2}{*}{$30 \pm 10$} & $1-2$ & $20.2 \pm 3.7 \mathrm{aA}$ & $8-48$ & $33.1 \pm 8.1 \mathrm{aA}$ & $2-86$ \\
\hline & $4-5$ & $23.5 \pm 6.3 \mathrm{aA}$ & $5-72$ & $40.5 \pm 5.4 \mathrm{aA}$ & $15-64$ \\
\hline \multirow[t]{2}{*}{$60 \pm 10$} & $1-2$ & $23.6 \pm 7.1 \mathrm{aA}$ & $4-76$ & $47.8 \pm 6.2 \mathrm{aA}$ & $27-87$ \\
\hline & $4-5$ & $26.8 \pm 8.2 \mathrm{aA}$ & $0-81$ & $42.3 \pm 6.5 \mathrm{aA}$ & $18-75$ \\
\hline \multicolumn{6}{|c|}{ Light intensity (lux) } \\
\hline \multirow[t]{2}{*}{$1000 \pm 100$} & $1-2$ & $11.4 \pm 2.4 \mathrm{bA}$ & $0-23$ & $29.6 \pm 6.1 \mathrm{bA}$ & $13-63$ \\
\hline & $4-5$ & $16.6 \pm 3.0 \mathrm{aA}$ & $0-35$ & $43.1 \pm 3.9 \mathrm{aA}$ & $26-67$ \\
\hline \multirow[t]{2}{*}{$7000 \pm 100$} & $1-2$ & $17.1 \pm 3.5 \mathrm{aA}$ & $0-41$ & $50.1 \pm 3.7 \mathrm{aA}$ & $29-67$ \\
\hline & $4-5$ & $21.9 \pm 6.4 \mathrm{aA}$ & $0-62$ & $39.9 \pm 7.8 \mathrm{aA}$ & $12-83$ \\
\hline
\end{tabular}

Means with different lower case letters indicate significant differences between temperatures, relative humidities or light intensities and means with different capital letters indicate differences between host ages at $\mathrm{p} \leq 0.05 \%$ (mortality: t-test, sex ratio: Chi-square); $\mathrm{n}=10$. 


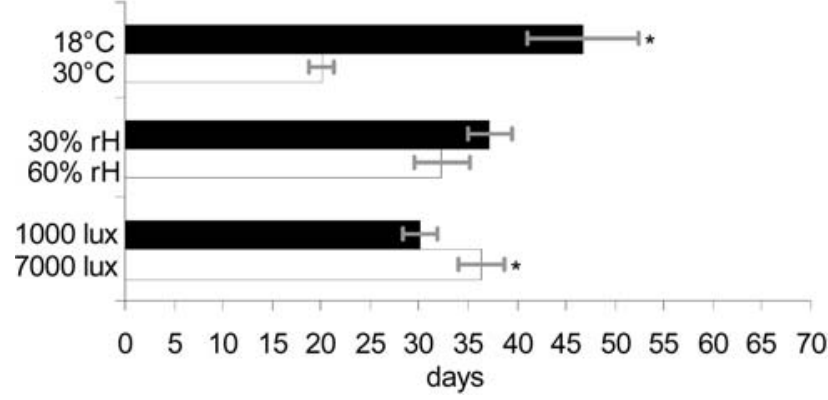

Fig. 1. Mean longevity of Aphelinus asychis females parasitizing 1-2 day old Aphis gossypii nymphs at different temperatures, relative humidities and light intensities (mean $\pm \mathrm{SE}$ ). (* indicates significant differences between temperatures, relative humidities or light intensities at $\mathrm{p} \leq 0.05$; Temperature \& relative humidity: T-test; Light intensity: Mann-Whitney-U-test, n $=10)$.
7000 than at 1000 lux. In the other experiments there were no significant differences in mortality.

The mean percentage of females at $30^{\circ} \mathrm{C}(38.0$ and $49.2 \%)$ was significantly higher than at $18^{\circ} \mathrm{C}(17.9$ and $27.6 \%$ ) when 1-2 and 4-5 day old aphid nymphs were used as hosts, respectively. The mean percentage of females was not affected by relative humidity. Regarding light intensity the higher light intensity of 7000 lux favoured females as the average percentage of females decreased significantly at the lower light intensity when 1-2 day old aphid nymphs were used as hosts.

When 1-2 day old $A$. gossypii nymphs were used as hosts the longevity of $A$. asychis females varied between 15 and 67 days, depending on temperature, relative humidity and light intensity (Fig. 1). At $18^{\circ} \mathrm{C}$ the mean

Post-

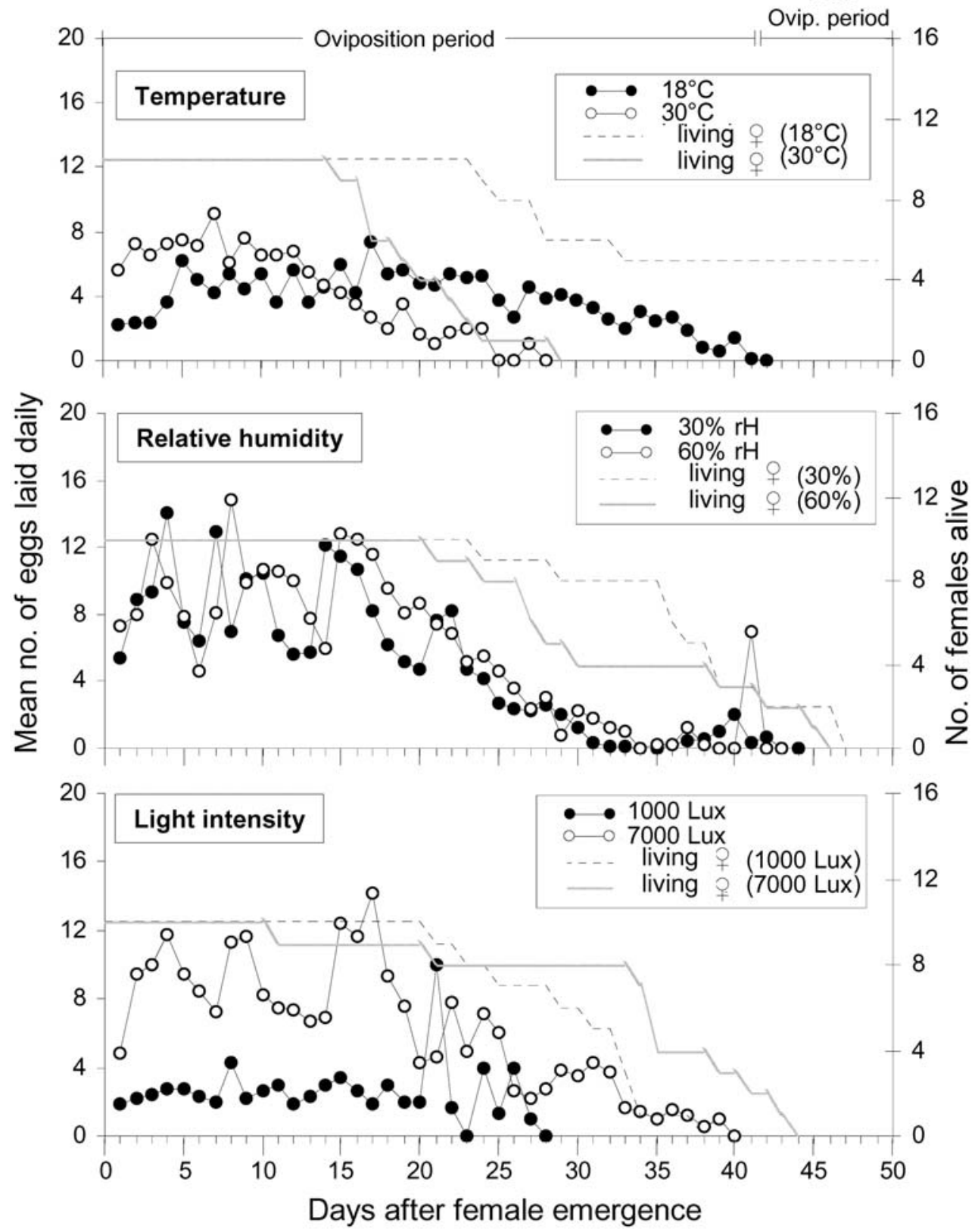

Fig. 2. Mean daily number of eggs laid by females of Aphelinus asychis parasitizing 1-2 day old Aphis gossypii nymphs at different temperatures, relative humidities and light intensities $(\mathrm{n}=10)$. 


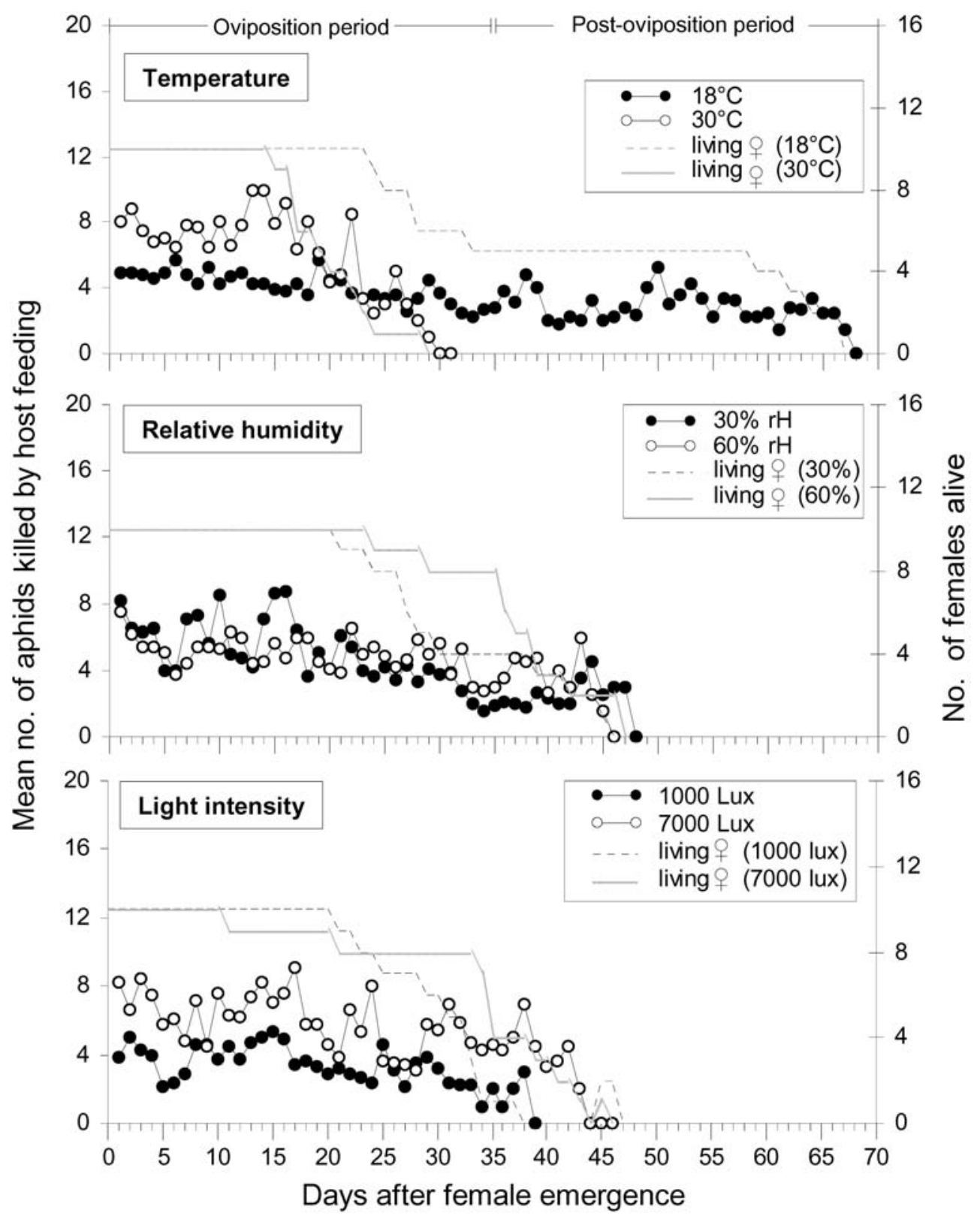

Fig. 3. Mean daily number of aphids killed by host feeding by Aphelinus asychis females when provided with 1-2 day old Aphis gossypii nymphs as hosts at different temperatures, relative humidities and light intensities $(\mathrm{n}=10)$.

longevity was significantly longer than at $30^{\circ} \mathrm{C}(47.2$ days versus 20.3 days).

Relative humidity had no effect on the longevity of the female parasitoid. The maximum longevity of 67 days was recorded at $18^{\circ} \mathrm{C}, 3000$ lux light intensity and $60 \%$ relative humidity. Regarding light intensity, the mean longevity was significantly longer at the higher illumination of 7000 lux (36.1 days) than at the lower illumination (30.1 days at 1000 lux).

The mean daily fecundity of $A$. asychis parasitizing 1-2 day old aphid nymphs and at the different climatic conditions is presented in Fig. 2. Because a surplus of aphids were offered to females of $A$. asychis, superparasitism did not occur. In all experiments the parasitoid started ovipositing on the first day after emergence and stopped on the $28-44^{\text {th }}$ day, depending on temperature, relative humidity and light intensity.

The mean number of eggs laid daily on the first day after emergence was 2.2 and $5.6 \mathrm{eggs} / \mathrm{O}$ at $18^{\circ} \mathrm{C}$ and $30^{\circ} \mathrm{C}$, respectively. Afterwards it fluctuated and reached a maximum on the $5^{\text {th }}$ day at $18^{\circ} \mathrm{C}$ and $7^{\text {th }}$ day at $30^{\circ} \mathrm{C}$. After that, the mean number of eggs laid each day decreased until no eggs were laid on the $28^{\text {th }}$ and $42^{\text {nd }}$ day after adult emergence at $30^{\circ} \mathrm{C}$ and $18^{\circ} \mathrm{C}$, respectively. The mean number of eggs laid on the first day after emergence was 5.4 and $7.3 \mathrm{eggs} / 9$ at $30 \%$ and $60 \% \mathrm{RH}$, respectively. Then it fluctuated in a similar manner at both humidities and decreased gradually; no eggs were laid after the $43^{\text {rd }}$ day. The mean daily fecundity was significantly higher at the higher illumination. At 7000 lux a female laid an average of 4.8 eggs on the first day after 


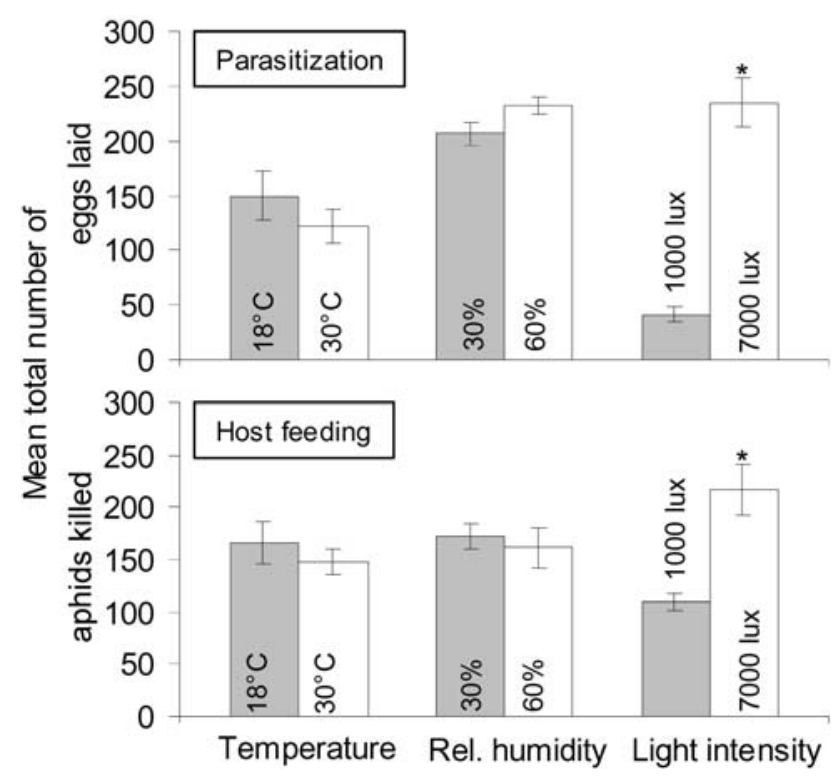

Fig. 4. Mean total number of eggs laid and aphids killed by Aphelinus asychis females when parasitizing 1-2 day old Aphis gossypii nymphs at different temperatures, relative humidities and light intensities (mean $\pm \mathrm{SE}$ ). (* indicates significant differences between temperatures, relative humidities or light intensities at $\mathrm{p} \leq 0.05$; t-test, $\mathrm{n}=10$ ).

emergence, while at 1000 lux 1.9 eggs were laid. During the first 20 days after emergence, the mean number of eggs laid at 7000 lux fluctuated between 4.3 and 14.2 eggs, while at 1000 lux it did not exceed $4.3 \mathrm{eggs} / 9$. The maximum at 7000 lux was $14.2 \mathrm{eggs} / 9$ on the $17^{\text {th }}$ day and the maximum at $1000 \mathrm{lux}$ was $10.0 \mathrm{eggs} / 9$ on the $21^{\text {st }}$ day. After this the mean fecundity decreased slowly until no eggs were laid after $27^{\text {th }}$ day and $39^{\text {th }}$ day at 1000 and 7000 lux, respectively.

Fig. 3 shows the mean daily host feeding by females of A. asychis at different temperatures, relative humidities and light intensities. In all experiments $A$. asychis females started host feeding on the first day after emergence and continued until they died.

The average number of aphids killed by host feeding was 4.9 at $18^{\circ} \mathrm{C}$ and 8.0 aphids $/ ~ q$ at $30^{\circ} \mathrm{C}$ on the first day after adult emergence, after which at $18^{\circ} \mathrm{C}$ it fluctuated between 1.5 and 5.2 aphids/ $q$ and decreased to zero on the $67^{\text {th }}$ day after emergence. At $30^{\circ} \mathrm{C}$ it increased to a maximum of 9.9 aphids/ $P$ and then decreased gradually to zero on the $31^{\text {st }}$ day after emergence. The average daily host feeding at $30 \%$ relative humidity was 8.2 aphids/ $q$ while at $60 \%$ relative humidity a parasitoid female host fed on 7.5 aphids on the first day after emergence. After that, the mean daily host feeding at $30 \%$ relative humidity increased and reached a maximum of 8.7 aphids/ + . At $60 \%$ relative humidity, the average of daily host feeding fluctuated between 3.8 and 6.6 aphids/ $q$ until day 43 and then approached zero on the $47^{\text {th }}$ day after emergence at both $30 \%$ and $60 \%$ RH. Depending on light intensity, the mean daily host feeding on the first day after emergence was higher at 7000 lux (8.2 aphids/ + ) than at 1000 lux (3.8 aphids/ $q$ ). While at 7000 lux the values then fluctuated between 3.1 and 9.1 aphids/ $q$ the mean daily host feeding at 1000 lux did not exceed 5.4 aphids/ + . Host feeding at 7000 lux approached zero on the $44^{\text {th }}$ day, which was slightly longer than that recorded at 1000 lux ( $39^{\text {th }}$ day).

Fig. 4 presents the mean total number of eggs laid and aphids killed by host feeding by $A$. asychis females during their entire life under different climatic conditions.

The total number of eggs laid at both temperatures, relative humidities and light intensities varied between 41.0 and $234.7 \mathrm{eggs} / \%$ and the total number of aphids killed by host feeding between 109.8 and 214.10 aphids/ $q$. While parasitization and host feeding were not influenced by temperature and relative humidity, they were both significantly affected by light intensity. At 7000 lux a female produced five times more eggs and consumed twice as many aphids by host feeding during its entire life than at 1000 lux.

\section{DISCUSSION}

The present study revealed that the biological traits studied were mostly affected by temperature and light intensity, whereas relative humidity and host age had only a slight effect.

Temperature is one of the most important factors affecting the population growth of arthropods. The relation between temperature and the developmental rate of insects is linear over most of the range of temperatures. As expected, the current study has demonstrated that the total developmental duration decreased as temperature increased. These findings are similar to those reported by Jackson \& Eikenbary (1971) and Bernal \& Gonzales (1993), who studied the life cycle of $A$. asychis parasitizing the greenbug Schizaphis graminum (Rondani) and the russian wheat aphid Diuraphis noxia (Mordvilko) (Sternorrhyncha: Aphididae). Mortality from mummification to emergence in the present study was not significantly influenced by temperature: there was only a slight increase in mortality at $30^{\circ} \mathrm{C}$. These findings are consistent with those of earlier studies on $A$. asychis parasitizing Rhopalosiphum maidis (Fitch) (Sternorrhyncha: Aphididae), S. graminum and Sipha flava (Forbes) (Sternorrhyncha: Aphididae), in which the values range from 18-35\% (Raney et al., 1971). Many experiments on aphelinids have shown that juvenile mortality is not significantly influenced by temperatures up to $32^{\circ} \mathrm{C}$ (Force \& Messenger, 1964; Tang \& Yokomi, 1995; Röhne, 2002). Aphidiinae species, on the other hand, such as Aphidius colemani Viereck, Lysiphlebus testaceipes Cresson and Lysiphlebia japonica Ashmead (Hymenoptera: Aphidiidae) have a higher juvenile mortality at higher temperatures (Van Steenis, 1993, 1994; Tang \& Yokomi, 1995; Deng \& Tsai, 1998; Ohta et al., 2001; Liu \& Tsai, 2002). One of the factors that affects the success or failure of a released parasitoid is the offspring sex ratio (Waage \& 
Hassell, 1982). The percentage of females was hardly affected by temperature. Contrary to earlier studies (Schlinger \& Hall, 1955; Raney et al., 1971), current results suggest that higher temperatures favoured the development of females, as the percentage of females was lower at the lower temperature. However, variations are probably caused by different experimental designs and different host species. The longevity of aphelinids depends on various factors, among which food and temperature are of special importance (Bernal et al., 1997). In all experiments $A$. asychis females were provided with the same amount of food, thus differences in longevity reflect the influence of temperature on this attribute. The observation, that longevity increased at the lower temperature is similar to that reported for other Aphelinus species by various authors (Starý, 1988; Raney et al., 1971; Bernal et al., 1997). Although the present study revealed that $A$. asychis females lived significantly longer at $18^{\circ} \mathrm{C}$ than at $30^{\circ} \mathrm{C}$, mean total parasitization and host feeding were not significantly influenced by temperature. As a consequence, the mean daily parasitization and host feeding during the first 20 days after emergence were higher at $30^{\circ} \mathrm{C}$ than at $18^{\circ} \mathrm{C}$. In general, Raney et al. (1973) reported that the number of aphids parasitized by $A$. asychis increase with increasing temperature up to about $26^{\circ} \mathrm{C}$, above which the number of mummies decreased with further increase in temperature. This is supported by the current results and those of Sengonca et al. (2007), who reported that $A$. asychis parasitized an average of 232.3 aphids $/ 9$ at $25^{\circ} \mathrm{C}$.

Light intensity in the current study significantly influenced the duration of development, the percentage of females, longevity, parasitization and host feeding. As $A$. asychis is an endoparasitoid, which completes its development inside its aphid host, light intensity usually is thought to have little effect on its development. Contrary to expectations, the current experiments revealed that development was significantly faster at the higher illumination and the proportion of females significantly higher at 7000 lux than at 1000 lux light intensity. In addition to the direct effect of light intensity on parasitoid larvae and pupae, their development is probably influenced by changes in aphid behaviour, such as a higher sucking rate or faster nymphal development. Moreover a higher aphid body temperature induced by radiation might have accelerated the growth of parasitoid larvae inside the aphids. According to Wyatt \& Brown (1977), light intensity and day length are important factors affecting the reproductive capacity of this aphid. In contrast, Auclair (1967) reports that high light intensity (550 lux or brighter) inhibits feeding and colonization. Aphids are sensitive to different wavelengths and intensities of light, but the nature of the effect is not clearly understood (Ebert \& Cartwright, 1997). However, there are no detailed studies on the influence of different light intensities and wavelengths on physiological processes occurring inside aphids and consequently their impact on the parasitoid development. In addition to the effect of light intensity on development, the present study showed that the longevity of $A$. asychis females was significantly longer at 7000 than at 1000 lux. It is well known that the foraging behaviour, parasitization and host feeding are strongly affected by light intensity, but this is the first report on the effect of longevity. Some authors indicate that parasitization by the whitefly parasitoid E. formosa starts at light intensities above 4000 lux and reaches maximum at 7300 lux (McDevitt, 1973; Scopes, 1973), light intensities below 1000 lux cause a decrease in parasitization. Van Lenteren et al. (1992) report that the aphelinid E. formosa, disperses even at low light intensities (500 lux or less). They suggest that at high light intensities they cover longer distances. Moreover they state that light intensity does not seem to have the same linear and absolute effect as temperature has on activity. These observations are in agreement with the current results: light intensity had a significant effect on parasitization and host feeding, but the effect was not linear. Low light intensity negatively affected parasitization, while at the higher light intensity parasitization was very high. In addition, parasitization at 7000 lux is similar to that at 3000 lux when relative humidity was varied. Low light intensity might have caused a reduced foraging behaviour. To ensure the success in biological control further investigations at lower and higher light intensities are needed to elucidate whether there is a possible threshold.

As expected, relative humidity did not have a pronounced effect on most of the traits studied. But, the current results indicate that the developmental duration of the parasitoid differed significantly at the two relative humidities tested. Similar to light intensity, the variations in parasitoid development were probably caused by direct effects of relative humidity on the parasitoid larvae or pupae (especially in mummified aphids) or by its effect on aphid development and behaviour, but there is no information on this in the literature. Contrary to earlier studies on the aphelinid Eretmocerus longipes Compere (Hymenoptera: Aphelinidae), a parasitoid of Aleurotuberculatus takahashi David et Subramaniam (Sternorrhyncha: Aleyrodidae) (Sengonca \& Liu, 1998), the adult emergence of $A$. asychis was not affected by humidities, below 35\% RH. However, such low humidity rarely occurs in greenhouses, so it is unlikely to be an important factor in the development of this parasitoid. But the relative humidity might be important when rearing $A$. asychis in mass culture for biological control.

The current results, for the same climatic conditions, indicated that the developmental duration was significantly influenced by host age. That the development in the older $A$. gossypii nymphs was significantly shorter than in the younger nymphs is consistent with the results of Sengonca et al. (2007).

In general, the current study suggests that the most important abiotic factors influencing the life cycle of $A$. asychis are temperature and light intensity. However, the most important trait of a biological control agent is whether its life cycle is well adapted to that of its aphid host, $A$. gossypii and the greenhouse conditions necessary for cucumber cultivation. The present study suggests that 
A. asychis conforms to those requirements. The parasitoid is well adapted to temperatures ranging from $18^{\circ} \mathrm{C}$ to $30^{\circ} \mathrm{C}$, while reproduction was optimal at $25^{\circ} \mathrm{C}$ (Sengonca et al., 2007). Numerous studies on the cotton aphid reveal that it is able to reproduce and survive at similar temperatures (Aldyhim \& Khalil, 1993; Van Steenis \& ElKhawass, 1995a, b). Although parasitization is lower at low light intensities, $A$. asychis is still able to survive and reproduce at 1000 lux. This might be important for maintaining populations of this beneficial in open rearing systems, which are often used in biological control programs. Hence, the short developmental duration, high proportion of females, long life span and high fecundity, as well as its temperature tolerance and life cycle well adapted to this aphid host, are properties that make it likely that $A$. asychis could be used in the biological control of the cotton aphid in greenhouses.

ACKNOWLEDGEMENTS. The authors thank E. Tatsumi, Graduate School of Agriculture, Kyoto Prefectural University, Japan, for kindly providing some individuals to establish a colony of $A$. asychis.

\section{REFERENCES}

Aldyhim Y.N. \& Khalil A.F. 1993: Influence of temperature and day length on population development of Aphis gossypii on Cucurbita pepo. Entomol. Exp. Appl. 67: 167-172.

AuClair J.L. 1967: Effects of light and sugars on rearing the cotton aphid, Aphis gossypii, on germ-free holidic diet. $J$. Insect Physiol. 13: 1247-1268.

BAI B. 1991: Conspecific superparasitism in 2 parasitoid wasps, Aphidius ervi Haliday and Aphelinus asychis Walker reproductive strategies influence host discrimination. Can. Entomol. 123: 1229-1237.

BAI B. \& MACKAUER M. 1990a: Oviposition and host-feeding patterns in Aphelinus asychis (Hymenoptera: Aphelinidae) at different aphid densities. Ecol. Entomol. 15: 9-16.

BAI B. \& MACKAUER M. 1990b: Host discrimination by the aphid parasitoid Aphelinus asychis (Hymenoptera: Aphelinidae) when superparasitism is not adaptive. Can. Entomol. 122: 363-372.

Bernal J. \& Gonzalez D. 1993: Temperature requirements of 4 parasites of the russian wheat aphid Diuraphis noxia. Entomol. Exp. Appl. 69: 173-182.

Bernal J.S., WagGoner M. \& Gonzalez D. 1997: Reproduction of Aphelinus albipodus (Hymenoptera: Aphelinidae) on russian wheat aphid (Hemiptera: Aphididae) hosts. Eur. J. Entomol. 94: 83-96.

Bernal J.S., Gonzalez D. \& David-Dimarino E. 2001: Overwintering potential in California of two russian wheat aphid parasitoids (Hymenoptera: Aphelinidae, Aphidiidae) imported from Central Asia. Pan.-Pac. Entomol. 77: 28-36.

BRodeUR J. \& RosenheIM J.A. 2000: Intraguild interactions in aphid parasitoids. Entomol. Exp. Appl. 97: 93-108.

Deng Y.X. \& Tsai J.H. 1998: Development of Lysiphlebia japonica (Hymenoptera: Aphidiidae), a parasitoid of Toxoptera citricida (Homoptera: Aphididae) at five temperatures. Fla Entomol. 81: 415-423.

Ebert T.A. \& CARTwright B. 1997: Biology and ecology of Aphis gossypii Glover (Homoptera: Aphididae). Southwest. Entomol. 22: 116-153.

Elliott N.C., Lee J.H. \& KindLeR S.D. 1999: Parasitism of several aphid species by Aphelinus asychis (Walker) and Aphe- linus albipodus Hayat and Fatima. Southwest. Entomol. 24: $5-12$.

ForCe D.C. \& Messenger P.S. 1964: Fecundity reproductive rates and innate capacity for increase of 3 parasites of Therioaphis maculata (Buckton ). Ecology 45: 706-715.

Furk C. \& Hines C.M. 1993: Aspects of insecticide resistance in the melon and cotton aphid, Aphis gossypii (Hemiptera: Aphididae). Ann. Appl. Biol. 123: 9-17.

JACKSON H.B. \& EIKENBARY R.D. 1971: Bionomics of Aphelinus asychis (Hymenoptera: Eulophidae) an introduced parasite of sorghum greenbug (Homoptera: Aphididae). Ann. Entomol. Soc. Am. 64: 81-85.

Liu Y.H. \& Tsai J.H. 2002: Effect of temperature on development, survivorship, and fecundity of Lysiphlebia mirzai (Hymenoptera: Aphidiidae), a parasitoid of Toxoptera citricida (Homoptera: Aphididae). Environ. Entomol. 31: 418-424.

McDevitT C.E.S. 1973: The effect of light on oviposition by Encarsia formosa. Project Report of the School of Biological Science. University of Bath, $30 \mathrm{pp}$.

Ohta I., Miura K. \& Kobayashi M. 2001: Life history parameters during immature stage of Aphidius gifuensis Ashmead (Hymenoptera: Braconidae) on green peach aphid, Myzus persicae (Sulzer) (Homoptera: Aphididae). Appl. Entomol. Zool. 36: 103-109.

Raney H.G., Coles L.W., Eikenbary R.D.M.R.D. \& Starks K.J. 1971: Host preference, longevity, developmental period and sex ratio of Aphelinus asychis with 3 sorghum-fed species of aphids held at controlled temperatures. Ann. Entomol. Soc. Am. 64: 169-176.

Raney H.G., Bridgwater F., Eikenbary R.D.M.R.D. \& MorRISON R.D. 1973: Predicting parasitism by Aphelinus asychis. Environ. Entomol. 2: 859-861.

RöHNE O. 2002: Effect of temperature and host stage on performance of Aphelinus varipes Forster (Hym., Aphelinidae) parasitizing the cotton aphid, Aphis gossypii Glover (Hom., Aphididae). J. Appl. Entomol. 126: 572-576.

SCHLIngER E.I. \& Hall J.C. 1959: A synopsis of the biology of 3 imported parasites (Hymenoptera: Braconidae, Eulophidae) of the spotted alfalfa aphid. J. Econ. Entomol. 52: 154-157.

SCOPES N.E.A. 1973: The effect of environment on the development and balance between pests and their natural enemies. IOBC/WPRS Bull. 73: 53-54.

Sengonca C. \& Liu B. 1998: Biological studies on Eretmocerus longipes Compere (Hym., Aphelinidae), a parasitoid of Aleurotuberculatus takahashi David et Subramaniam (Hom., Aleyrodidae) in the laboratory. J. Appl. Entomol. 122: 207-211.

Sengonca C., Schirmer S. \& Blaeser P. 2007: Life table of the aphid parasitoid Aphelinus asychis (Walker) (Hym., Aphelinidae) with different age groups of Aphis gossypii Glover (Hom., Aphididae) as host. J. Plant Dis. Prot. (in press).

StarÝ P. 1988: Aphelinidae. In Minks A.K. \& Harrewijn P. (eds): Aphids. Their Biology, Natural Enemies and Control. Vol 2B. Elsevier, Amsterdam, pp. 185-188.

TANG Y.Q. \& Yокомі R.K. 1995: Temperature-dependent development of three hymenopterous parasitoids of aphids (Homoptera: Aphididae) attacking citrus. Environ. Entomol. 24: 1736-1740.

TAtsumi E. \& TAKAda H. 2005a: Evaluation of Aphelinus asychis and Aphelinus albipodus (Hymenoptera: Aphelinidae) as biological control agents against three pest aphids. Appl. Entomol. Zool. 40: 379-385.

TAtsumi E. \& TAKada H. 2005b: Effects of photoperiod and temperature on adult oligopause of Aphelinus asychis and larval diapause of A. albipodus (Hymenoptera: Aphelinidae). Appl. Entomol. Zool. 40: 447-456. 
TAtsumi E. \& TAKada H. 2006: Differences in dormancy characteristics among populations of Aphelinus asychis (Hymenoptera: Aphelinidae). Jpn. J. Appl. Entomol. Zool. 50: 72-74.

Van Lenteren J., Szabo P. \& Huisman P.W.T. 1992: The parasite-host relationship between Encarsia formosa Gahan (Hymenoptera: Aphelinidae) and Trialeurodes vaporariorum (Westwood) (Homoptera: Aleyrodidae) - adult emergence and initial dispersal pattern of E. formosa. J. Appl. Entomol. 114: 392-399.

VAN Schelt J. 1993: Market-driven research and development in biological control. Pestic. Sci. 37: 405-409.

VAn Steenis M.J. 1993: Intrinsic rate of increase of Aphidius colemani Vier. (Hym., Braconidae), a parasitoid of Aphis gossypii Glov. (Hom., Aphididae), at different temperatures. J. Appl. Entomol. 116: 192-198.

VAN SteEnIS M.J. 1994: Intrinsic rate of increase of Lysiphlebus testaceipes Cresson (Hym., Braconidae), a parasitoid of Aphis gossypii Glover (Hom., Aphididae) at different temperatures. J. Appl. Entomol. 118: 399-406.

VAN STEENIS M.J. 1995: Evaluation of four aphidiine parasitoids for biological control of Aphis gossypii. Entomol. Exp. Appl. 75: $151-157$.

Van SteEnIS M.J. \& El-Khawass K.A.M.H. 1995a: Behavior of Aphidius colemani searching for Aphis gossypii - functional- response and reaction to previously searched aphid colonies. Biocontrol Sci. Techn. 5: 339-347.

Van Steenis M.J. \& El-Khawass K.A.M.H. 1995b: Life history of Aphis gossypii on cucumber - influence of temperature, host-plant and parasitism. Entomol. Exp. Appl. 76: 121-131.

Villatte F., Auge D., Touton P., Delorme R. \& Fournier D. 1999: Negative cross-insensitivity in insecticide-resistant cotton aphid Aphis gossypii Glover. Pestic. Biochem. Physiol. 65: $55-61$.

WaAge J.K. \& Hassell M.P. 1982: Parasitoids as biologicalcontrol agents - a fundamental approach. Parasitology 84: 241-268.

WANG K.Y., LiU T.X., Jiang X.Y. \& Yi M.Q. 2001: Crossresistance of Aphis gossypii to selected insecticides on cotton and cucumber. Phytoparasitica 29: 393-399.

WyatT I. \& BRown S.J. 1977: The influence of light intensity, day length and temperature on increase of four glasshouse aphids. J. Appl. Ecol. 14: 391-399.

YU D.S. 1992: Effects of photoperiod and temperature on diapause of 2 Aphelinus spp (Hymenoptera: Aphelinidae) parasitizing the russian wheat aphid. Can. Entomol. 124: 853-860.

ZoHDY N.Z.M. 1976: Effect of food of Myzus persicae Sulzer on hymenopterous parasite Aphelinus asychis Walker. Oecologia 26: 185-191.

Received June 29, 2007; revised and accepted October 2, 2007 